\title{
Nuestro Chile y sus terremotos
}

Our Chile and earthquakes

Juan Parrochia Beguin [1985]

\section{Filiación}

Ex Profesor Titular del D. Urbanismo de la F.A.U. de la Universidad de Chile

\section{Resumen}

Reflexiones que hizo el autor en 1985 respecto del terremoto de ese año en Santiago de Chile, para recordar cómo ha cambiado - muy poco- la mentalidad y acción post terremoto.

\section{Palabras clave}

Terremotos en Chile; Santiago de Chile; desastres.

\section{Abstract}

Reflections made by the author in 1985 regarding the earthquake of that year in Santiago, Chile, to remember how little has changed the mentality and post earthquake action.

\section{Key words}

Earthquakes in Chile; Santiago, Chile; disasters.

\section{Sumario}

Nuestra trayectoria por los terremotos

La protesta de nuestra débil infraestructura

Negocios a costa de los afectados

A partir de la urgencia...

\section{Nuestra trayectoria por los terremotos}

Recordamos claramente los efectos desastrosos del terremoto de 1939, si bien estábamos entonces en Viña del Mar, en el segundo piso de una casa de tabiquería con relleno de adobillo, donde se sintió el sismo con bastante fuerza. Ocho días después tuvimos la oportunidad de ir a la zona afectada en el primer tren que pudo pasar hacia el Sur.

Por problemas de daños en casa de familiares tuvimos que acudir al terremoto de Traiguén en 1949.

En 1958, fuimos destacados por el Ministerio de Obras Públicas de Chile para inspeccionar, en los días siguientes al movimiento telúrico, los efectos del terremoto de Las Melozas, en el Cajón del Maipo. Igual misión tuvimos en 1960, para apreciar los daños de los sismos de mayo en Los Ángeles, Angol, Traiguén, Victoria y Temuco. En esa oportunidad, refundamos con Ernesto Pinto L., entonces Vicepresidente de la CORVI, los pueblos de Nueva Toltén y de Nuevo Puerto Saavedra, ambos arrasados, además, por el maremoto posterior. 
Entonces, nos radicamos en Valdivia, para participar en su reconstrucción y formular su Plano Regulador, al igual que después del "Riñihuaso", lo hicimos en Los Lagos.

En 1967 y en 1971 tuvimos la oportunidad de participar en los trabajos de los terremotos de La Ligua, que afectaron la $\mathrm{V}$ Región por dos veces en cinco años.

Ahora [1985], en la Universidad de Chile, nos correspondió, junto a varios profesionales, observar los efectos del terremoto del 3 de marzo, en Melipilla, San Antonio, Curacaví, Valparaíso, Santiago, y en nuestra propia casa.

\section{La protesta de nuestra débil infraestructura}

Los terremotos en Chile son la protesta de nuestra débil infraestructura, de nuestras viviendas de mala calidad, de nuestras construcciones mal tenidas.

Los terremotos son la voz del déficit de viviendas.

Los terremotos son los strip-tease de nuestras edificaciones que sacuden sus revestimientos y muestran sus cuerpos desnudos, desnutridos y llenos de cicatrices de sucesivas calamidades.

Así vemos sus deterioradas estructuras de maderas podridas, de hormigones pobres y mal fraguados, de enfierraduras insuficientes, de construcciones mixtas inadecuadas, de débiles materiales de revestimientos, de instalaciones de servicios mal conservados, de fundaciones mal resueltas, de techumbres y tijerales inadecuados...

Mucho de todo esto, tanto por despreocupación, como por falta de recursos, y mucho también por abaratar los precios sin disminuir las ganancias.

Los terremotos son gritos de muerte, de hastío, de cansancio. Son las estadísticas que se muestran en su verdadero significado físico para los ciegos y los sordos.

Rápidamente, particulares y autoridades emprenden con agilidad, generosidad pudor, la tarea de volver a tapar y vestir los cuerpos desnudos, y disimular con estucos, planchas y mediaguas, la impúdica demostración de la naturaleza rebelde y escandalosa.

Se trata de hacer desaparecer los escombros con gran rapidez, apagar el grito desesperado de la tierra y volver a la "normalidad", ¿cuál normalidad?, la normalidad de la pobreza, de la cesantía, de las construcciones sin mantenimiento, de las inadecuadas viviendas mal construidas o insuficientemente calculadas.

\section{Negocios a costa de los afectados}

Pero en todo este desastre siempre hay espacio para hacer brillantes negocios, a costa de los afectados: sean guerras, tempestades, sismos, inundaciones, incendios, crisis económicas, dictaduras, deflación, pérdida de la industria, sequía, cesantía. Todas ellas 
permiten, para un hábil, objetivo y pragmático empresario, hacer con decoro y sensibilidad, buenas operaciones comerciales y financieras.

El día del fin del mundo habrá tal cantidad de chatarra en la tierra, que Onassis parecerá insignificante con los negocios que hizo después de la Segunda Guerra Mundial, comparados con los que se podrán hacer ese día.

Todos los materiales de construcción se comportan perfectamente bien en un sismo: la teja, el adobe, el ladrillo, el acero, el panel, la plancha, todo funciona si se cumplen las exigencias de la técnica que ellos requieren, y se le da la conservación que les corresponde.

En el $99 \%$ de los casos de derrumbe, hemos podido apreciar que ello no se cumplía.

Es más fácil culpar al pesado y silencioso material de construcción o al tembloroso sismo, que deducir una útil experiencia de los que proponen y aprueban malos terrenos para construir; de los que no proyectan adecuadamente los edificios y sus estructuras; de los que no supervigilan, ni inspeccionan las construcciones; de los operarios que hacen mal su trabajo, o que al hacerlo, debilitan las estructuras de los edificios; de los que especulan con la vivienda y edificios; de los que especulan con la vivienda y tratan de obtener los máximos beneficios, disminuyendo calidad y cantidad en espacio, secciones, duración, profundidad, proporción, intervención, profesional especializada, y miles de aspectos muy remunerativos que hacen "grande" al que los goza y terriblemente débil e ingenuo al que los sufre.

Hemos visto como se re-tapan las viviendas con los mismos materiales fallados y fatigados que causaron el derrumbe frente al sismo, listas para volver a derrumbarse en el próximo, que todos suponen será en 10 años o más..., a lo mejor toca en otra parte y no pasará nada. ¿Quién puede pensar a tan largo plazo cuando muchos no tienen resuelta ni siquiera su alimentación del día?

Sólo se pueden enfrentar con racionalidad un terremoto o cualquier otra calamidad, cuando la gente, aunque pobre, tiene trabajo y esperanzas en el futuro.

En Chile, el terremoto es una calamidad sobre muchas otras calamidades sucesivas. En el fondo, es parte de nuestro destino, y una calamidad más o menos, no hace mucha diferencia.

Si este terremoto de 1985 se ha estimado con un daño del orden de 1.000 millones de dólares, y se reparará con un par de cientos, solamente, nuestro capital nacional se habrá empobrecido en la diferencia de esas dos cifras.

Si el terremoto ha dañado el país en mil millones de dólares, ¿a cuántos terremotos equivale la deuda de 21.000 millones de dólares, que actualmente nos embarga? Con la esperanza de que el $30 \%$ de esa deuda corresponda a inversiones productivas, el resto representa más de un terremoto al año, en los últimos 12 años.

O sea, no pasa nada nuevo en Chile, con el sismo de marzo de 1985. 
Por desgracia, en la situación económica en que estamos, el terremoto no es el disparo que inicia "una carrera en la pista del desarrollo".

\section{A partir de la urgencia...}

Amparados por la urgencia:

-se ocuparán nuevos terrenos inadecuados para urbanizar, -se tomarán tierras agrícolas productivas, o suelos de mala calidad de fundación, - las estructuras sociales no serán respetadas, -las agrupaciones humanas de damnificados serán mayores que las recomendables, -se crearán nuevos "ghettos"...

-no podrá aprovecharse la oportunidad para renovar, rehabilitar, sanear, -no se mejorarán los trazados de vías insuficientes, -se disminuirán las áreas libres y verdes, -los pueblos se "desplanificarán" aún más, -aparecerán nuevos problemas de transporte, viviendas, abastecimientos y servicios, -aumentarán los "allegados", -habrá un mayor déficit de viviendas en las áreas rurales y urbanas, -las infraestructuras de caminos, puentes y puertos, serán más deficitarias y sufrirán mayor desgaste, disminuyendo su vida útil, -no aumentará la demanda de arquitectura, y se perderán muchos patrimonios arquitectónicos históricos, -no se clarificará nada sobre ciertos materiales de construcción que tienen fuertes debilidades intrínsecas frente a los sismos, sus propios fabricantes estarán a la cabeza de la reconstrucción, junto con la autoridad.

Todo seguirá igual, en un nivel más deprimido, con los mismos errores, y en la misma irresponsabilidad e igual fatalismo.

Este terremoto sólo será bajar unos escalones más en nuestra calidad de vida nacional.

No habrá mayor empleo, porque gran parte de las reparaciones se están haciendo con trabajadores temporales, o son "pololos", y los trabajos mayores, se están haciendo con los mismos recursos que se habían programado para algunas escasas obras normales, que no se harán o se postergarán.

En pocos meses más, este terremoto también se habrá olvidado, frente a otros hechos, aún más graves.

Si no olvidáramos nuestras desgracias, no podríamos vivir ${ }^{1}$.

1 Manuscrito de abril de 1985, publicado parcialmente como: "Enjuiciamiento al sismo: Ideas buscando cauce", en revista AUCA N49: Anatomía de un Sismo, agosto de 1985, pp. 29-36. 